\title{
Positive Association between TGFB1 Gene and Susceptibility to Idiopathic Scoliosis in Bulgarian Population
}

\author{
Svetla Nikolova $\left(\mathbb{D},{ }^{1}\right.$ Milka Dikova, ${ }^{2}$ Dobrin Dikov, ${ }^{2}$ Assen Djerov, ${ }^{2}$ Alexey Savov $\left(D^{2}{ }^{3}\right.$ \\ Ivo Kremensky $\left(\mathbb{D},{ }^{4}\right.$ and Alexandre Loukanov ${ }^{5}$ \\ ${ }^{1}$ Laboratory of Medical Genetics and Molecular Biology, University Hospital Lozenetz, Sofia University "St. Kliment Ohridski", \\ 1 Kozyak St., Sofia 1407, Bulgaria \\ ${ }^{2}$ University Orthopedic Hospital "Professor Boycho Boychev", Medical University-Sofia, 56 Nikola Petkov Blvd., Sofia 1614, Bulgaria \\ ${ }^{3}$ National Genetic Laboratory, University Hospital "Maichin Dom", Medical University-Sofia, 2 Zdrave St., Sofia 1431, Bulgaria \\ ${ }^{4}$ Molecular Medicine Center, Medical University-Sofia, 2 Zdrave St., Sofia 1431, Bulgaria \\ ${ }^{5}$ Graduate School for Science and Engineering, Saitama University, 255 Shimookubo, Sakura-ku, Saitama 338-8570, Japan
}

Correspondence should be addressed to Svetla Nikolova; snikolova83@abv.bg

Received 21 February 2018; Revised 8 May 2018; Accepted 12 June 2018; Published 18 July 2018

Academic Editor: Jonathan S. Reichner

Copyright (@) 2018 Svetla Nikolova et al. This is an open access article distributed under the Creative Commons Attribution License, which permits unrestricted use, distribution, and reproduction in any medium, provided the original work is properly cited.

\begin{abstract}
Idiopathic scoliosis (IS) is a common medical condition beginning in childhood and characterized by strong evidence for a genetic susceptibility to three-dimensional spinal deformity. The primary goal of the current case-control study is to examine the association between the TGFB1 $(-509 \mathrm{C} / \mathrm{T})$ functional polymorphic variant and genetic predisposition to IS in the Bulgarian population and the genotype-phenotype correlations in distinct case-control subgroups based on age at onset, family history, and gender. A total of 127 patients with primary scoliosis and 254 gender-matched control subjects were recruited. The mean Cobb angle was $53.8 \pm 21.2^{\circ}$. Genotyping of cases and controls was performed using the TaqMan real-time amplification technique. The results were processed statistically using Pearson's Chi-squared test and Fisher's exact test with a value of $p$ less than 0.05 as statistically significant. The polymorphic T allele and TT genotype were associated with a greater incidence of IS and can be considered as predisposing factors with a moderate effect on deformity development. The current results suggested that there was a genetic predisposition in early and late onset IS and familial, sporadic, and female cases. Nevertheless, replication studies are needed to reveal the relationship between the TGFB1 locus and certain subtypes of IS in different populations.
\end{abstract}

\section{Introduction}

While mutations are the root cause of monogenic diseases and rare syndromes, functional genetic polymorphisms can often be associated with the etiopathogenesis of multifactorial diseases and common medical conditions. Association studies (candidate-gene and genome-wide case-control association studies) remain the leading approach for identification of genetic variants associated with complex human diseases. Idiopathic scoliosis (IS) is a common medical condition beginning in childhood and characterized by strong evidence for a genetic susceptibility to three-dimensional spinal deformity [1]. Adolescent idiopathic scoliosis (AIS) beginning after 10 years of age is the most common type of spine deformity [2].
Transforming growth factor beta 1 (TGFB1) is a multifunctional cytokine whose expression is associated with the physiological processes of growth, differentiation, regeneration, and stress response in many cell types [3-5]. Dickinson et al. [6] reported high transcript and/or protein levels in connective tissues during the periods of active morphogenesis, suggesting that TGFB1 is an important factor for their growth and differentiation. The results from two studies $[7,8]$ in AIS patients of Asian descent also indicated a marked increase in TGFB1 expression level at the concave side of the spinal curve compared to the convex side. This phenomenon suggests the involvement of TGFB1 as an etiological factor or a secondary factor in the development of the spine deformity. The increase of the TGFB1 level in the apical articular processes of the concave side of the 
curve in AIS may be due to the reconstruction of the extracellular matrix and the compensatory reactions which are caused by abnormal biomechanical forces, especially compressive stresses $[7,8]$. In a study of 9 IS patients of European descent, no differences in TGFB1 expression were found between paraspinal muscles of both sides of the curve [9].

A single nucleotide polymorphism (SNP), TGFB1 $(-509 \mathrm{C} / \mathrm{T} ;-1347 \mathrm{C} / \mathrm{T})$, affects transcription and plasma levels of the protein product. Shah et al. [10] found that the different expression levels are determined by the suppression of transcription through the activator protein AP1. In vitro and in vivo, the AP1 complex containing JunD and c-Fos was found to bind to the TGFB1 promoter only in the presence of the wild type allele $(-1347 \mathrm{C})$. Thus, elevated levels of TGFB1 are associated with the polymorph allele $(-1347 \mathrm{~T})$ due to a loss of negative regulation by AP1 [10].

A study in a Russian population sample (300 cases/300 controls) revealed a genetic association between TGFB1 $(-509 \mathrm{C} / \mathrm{T})$ and a predisposition to AIS. In the group of female patients, TGFB1 $(-509 \mathrm{C} / \mathrm{T})$ correlated with both the age of disease onset and curve severity [11]. A Chinese replication study (1251 cases/994 controls) did not confirm the association with the predisposition but with the mean Cobb angle in AIS patients [12]. The outcome measure of the aforementioned molecular genetic studies was the most common form of scoliosis-AIS. At the same time, there is limited available research on specific forms based on age at disease onset, family history, gender of the patients, and so on. Different genetic factors may be involved in the etiopathogenesis of early and late onset scoliosis as well as progressive and nonprogressive scoliosis, familial and sporadic cases, and male and female scoliosis. Wherefore, additional research is needed to clarify the possible contribution. The primary goal of the current case-control study is to examine

(i) the association between the TGFB1 (-509C/T) functional polymorphic variant and genetic predisposition to IS in the Bulgarian population;

(ii) the genotype-phenotype correlations in distinct case-control subgroups based on age at disease onset, family history, and gender.

\section{Materials and Methods}

2.1. Materials. A total of 127 patients with primary scoliosis and 254 gender-matched control subjects were recruited. For the aims of the current study, an informed consent was obtained from all individual participants or their parents in the case of minor patients. All work was conducted in accordance with the Declaration of Helsinki (1964). The responsible ethical committee of Medical University-Sofia approved the experiments (number 2987/2012).

The clinical diagnostic protocol included anamnesis, physical examination with Adam's forward bend test and a scoliometer, and radiographic studies of the spine in patients. The minimal value of the Cobb angle to define scoliosis was $10^{\circ}$. The mean Cobb angle was $53.8 \pm 21.2^{\circ}$. Secondary scoliosis (congenital, neuromuscular, syndrome-related, etc.) was excluded. Thereafter, the cases were divided into three subgroups according to the disease onset: infantile idiopathic scoliosis (IIS) - up to 3 years of age $(n=4)$; juvenile idiopathic scoliosis (JIS) - from 4 to 10 years of age $(n=26)$; and adolescent idiopathic scoliosis (AIS) - from greater than 10 to 18 years of age $(n=97)$. The mean age of idiopathic scoliosis onset was $11.2 \pm 2.9$ years. Finally, the patients were divided into two subgroups by gender-females $(n=102)$ and males $(n=25)$ and according to family anamnesis-familial $(n=34)$ and sporadic $(n=93)$ cases.

The control group had the same gender distribution-females $(n=204)$ and males $(n=50)$. Anamnesis, physical examination, and previous available spinal roentgenographies excluded mild scoliosis among the control subjects. All the controls were selected among skeletally matured individuals over 18 years of age to exclude primary scoliosis at a later stage.

2.2. Methods. Automated magnetic bead-based extraction of genomic desoxyribonucleic acid (DNA) from peripheral venous blood samples by a chemagic DNA Blood $10 \mathrm{k} \mathrm{Kit}$ (PerkinElmer, Baesweiler, Germany) was performed using a chemagic Magnetic Separation Module I (PerkinElmer, Baesweiler, Germany) according to the manufacturer's instructions.

Real-time amplification by a TaqMan SNP Genotyping Assay available under assay ID C_8708473_10 (Thermo Fisher Scientific, USA) on an ABI Prism 7900HT Sequence Detection System (Thermo Fisher Scientific, USA) was used according to the manufacturer's recommendations for TGFB1 ( $r$ 1800469) genotyping. All samples were run in duplicate in $5 \mu \mathrm{l}$ of reaction mix containing $2 \mu \mathrm{l}$ of DNA (10 ng/ $/$ l), $2.5 \mu \mathrm{l}$ of $2 \mathrm{x}$ TaqMan Genotyping Master Mix (Thermo Fisher Scientific, USA), $0.125 \mu \mathrm{l}$ of 40x TaqMan SNP Genotyping Assay (Thermo Fisher Scientific, USA), and $0.375 \mu \mathrm{l}$ of $\mathrm{dH}_{2} \mathrm{O}$. TaqMan real-time polymerase chain reaction (PCR) was performed with an initial denaturation of 10 minutes at $95^{\circ} \mathrm{C}$. The following thermal cycle was repeated 40 times: denaturation at $95^{\circ} \mathrm{C}$ for 15 seconds, annealing at $60^{\circ} \mathrm{C}$ for 60 seconds, and extension at $72^{\circ} \mathrm{C}$ for 15 seconds.

The results were processed statistically using Pearson's Chi-squared test for the general sample $(N=381)$ and the larger clinical subgroups $(N>300)$ or Fisher's exact test for the smaller clinical subgroups $(N<300)$ with a value of $p$ less than 0.05 as statistically significant. Odds ratios (OR) and risk ratios (RR) with 95\% confidence interval (CI) were also calculated (IBM SPSS 19.0, NY, USA).

\section{Results}

The genotype and allele frequencies of TGFB1 (-509C/T) were analyzed in the general group and the distinct subgroups based on disease onset, family history, and gender. Each patient group was compared to the total number of controls except for both of the gender groups which were compared to twice as many gender-matched controls. We examined the possible genetic predisposition using the following inheritance models: codominant (TT versus CC), dominant 
TABLE 1: Genotype and allele distribution in different subgroups of idiopathic scoliosis.

\begin{tabular}{|c|c|c|c|c|c|c|}
\hline \multirow{2}{*}{ Group } & & \multicolumn{3}{|c|}{ Genotypes, $N$} & \multicolumn{2}{|c|}{ Alleles, $N$} \\
\hline & & TT & $\mathrm{TC}$ & $\mathrm{CC}$ & $\mathrm{T}$ & $\mathrm{C}$ \\
\hline \multirow{2}{*}{ General $\left(n_{1}=127, n_{2}=254\right)$} & Cases & 64 & 51 & 12 & 179 & 75 \\
\hline & Controls & 82 & 126 & 46 & 290 & 218 \\
\hline \multirow{2}{*}{ AIS $\left(n_{1}=97, n_{2}=254\right)$} & Cases & 47 & 42 & 8 & 136 & 58 \\
\hline & Controls & 82 & 126 & 46 & 290 & 218 \\
\hline \multirow{2}{*}{ JIS $\left(n_{1}=26, n_{2}=254\right)$} & Cases & 15 & 8 & 3 & 38 & 14 \\
\hline & Controls & 82 & 126 & 46 & 290 & 218 \\
\hline \multirow{2}{*}{ FIS $\left(n_{1}=34, n_{2}=254\right)$} & Cases & 16 & 17 & 1 & 49 & 19 \\
\hline & Controls & 82 & 126 & 46 & 290 & 218 \\
\hline \multirow{2}{*}{$\operatorname{NFIS}\left(n_{1}=93, n_{2}=254\right)$} & Cases & 48 & 34 & 11 & 130 & 56 \\
\hline & Controls & 82 & 126 & 46 & 290 & 218 \\
\hline \multirow{2}{*}{ Males $\left(n_{1}=25, n_{2}=50\right)$} & Cases & 13 & 10 & 2 & 36 & 14 \\
\hline & Controls & 20 & 22 & 8 & 62 & 38 \\
\hline \multirow{2}{*}{ Females $\left(n_{1}=102, n_{2}=204\right)$} & Cases & 51 & 40 & 11 & 142 & 62 \\
\hline & Controls & 63 & 103 & 38 & 229 & 179 \\
\hline
\end{tabular}

AIS—adolescent idiopathic scoliosis; JIS—juvenile idiopathic scoliosis; FIS—familial idiopathic scoliosis; NFIS—nonfamilial idiopathic scoliosis; $N$-number of genotypes or alleles; $n_{1}$-number of cases; $n_{2}$-number of controls.

$(\mathrm{TT}+\mathrm{CT}$ versus $\mathrm{CC})$, recessive (TT versus $\mathrm{CT}+\mathrm{CC})$, and allelic ( $\mathrm{T}$ versus $\mathrm{C}$ ). The genotypes were in Hardy-Weinberg equilibrium.

In the overall group, the frequencies of the homozygous TT genotype and polymorphic $\mathrm{T}$ allele of TGFB1 $(-509 \mathrm{C} / \mathrm{T})$ were higher in the cases than that in the controls (TT versus CT versus CC, $p=0.001, \chi^{2}=13.05$ and $\mathrm{T}$ versus $\mathrm{C}, p=0.0003, \chi^{2}=12.35$, resp.). The homozygous TT genotype was associated with a 1.56 times higher risk (TT versus $\mathrm{CT}+\mathrm{CC}, \mathrm{RR}=1.56,95 \% \mathrm{CI}: 1.22-2.00$ ), and the $\mathrm{T}$ allele with a 1.23 times higher risk ( $\mathrm{T}$ versus $\mathrm{C}$, $\mathrm{RR}=1.23$, 95\% CI: $1.11-1.38$ ), for the development of idiopathic scoliosis in Bulgarian patients. The obtained results suggested that the TT genotype should be considered as a risk factor with a moderate individual impact $(56 \%$ greater risk of deformity) as a part of the genetic predisposition to disease in the Bulgarian population.

In the subgroups of AIS, JIS, familial idiopathic scoliosis, sporadic idiopathic scoliosis, and females, the observed genotype and allele frequencies of TGFB1 $(-509 \mathrm{C} / \mathrm{T})$ differed also considerably between the cases and controls $\left(p<0.05, \chi^{2}\right.$-test or Fisher's exact test). The highest RR value was recorded in the subgroup of JIS (TT versus CT $+\mathrm{CC}, \mathrm{RR}=1.79,95 \% \mathrm{CI}$ : 1.23-2.6, Fisher's exact test). The four cases of IIS were excluded. By enrolling too few subjects, the study will not have enough statistical power to detect any difference (type II error). No statistically significant association was detected in the small subgroup of males ( $p>0.05$, Fisher's exact test).

The genotype and allele distributions are presented in Table 1. $P$ values and ORs of the genotypes and alleles under the examined inheritance models are summarized in Table 2.

Then, we divided the female cases and significant association was detected in the subgroups with JIS, AIS and familial and sporadic forms of scoliosis $(p<0.05) . P$ values and ORs of the genotypes and alleles under the examined inheritance models are summarized in Table 3.

The obtained results reveal that the recessive model, having the lowest $p$ value, best explains the inheritance pattern of the risk TT genotype. The recessive model in the four subgroups is presented graphically in Figure 1.

\section{Discussion}

The functional polymorphism TGFB1 (-509C/T) was associated with AIS from two previous case-control studies in Asian and Caucasian population groups [11, 12]. In the current candidate-gene association study, the genotype and allele frequencies of TGFB1 $(-509 \mathrm{C} / \mathrm{T})$ were compared between patients and controls in a population of East European descent. In the general group, the polymorphic $\mathrm{T}$ allele and the homozygous TT genotype were associated with a greater incidence of idiopathic scoliosis and can be considered as a risk allele and a risk genotype, respectively, in the Bulgarian population ( $R R>1.5$ ).

The outcome measure of most of the association studies (candidate-gene or genome-wide association studies) was the most common form of scoliosis-AIS [13-20]. At the same time, available research on the early onset scoliosis (before 8-10 years of age) is still insufficient to establish genotype-phenotype correlations. Therefore, we included patients between 1 and 15 years of age at the onset of primary scoliosis. In the AIS subgroup, the results were similar to those in the total sample and in the JIS subgroup. A statistically significant association was also detected (Table 2). Larger replication studies are needed to confirm the novel association with early onset scoliosis predisposition.

Both in the familial and nonfamilial subgroups, the carriage of the $\mathrm{T}$ allele and $\mathrm{TT}$ genotype was associated with a susceptibility to idiopathic scoliosis (as shown in Table 2). 
TABLE 2: Inheritance models in different subgroups of idiopathic scoliosis.

\begin{tabular}{|c|c|c|c|}
\hline Group & Genetic model & $P$ value & OR $(95 \%$ CI $)$ \\
\hline \multirow{4}{*}{ General } & Codominant & 0.0020 & $2.99(1.46-6.11)$ \\
\hline & Recessive & 0.0006 & $2.13(1.38-3.29)$ \\
\hline & Dominant & 0.0265 & $2.12(1.08-4.16)$ \\
\hline & Allelic & 0.0003 & $1.79(1.30-2.47)$ \\
\hline \multirow{4}{*}{ AIS } & Codominant & 0.0036 & $3.30(1.43-7.57)$ \\
\hline & Recessive & 0.0049 & $1.97(1.22-3.18)$ \\
\hline & Dominant & 0.0219 & $2.46(1.12-5.43)$ \\
\hline & Allelic & 0.0016 & $1.76(1.24-2.51)$ \\
\hline \multirow{4}{*}{ JIS } & Codominant & 0.1189 & $2.80(0.77-10.2)$ \\
\hline & Recessive & 0.0157 & $2.86(1.26-6.50)$ \\
\hline & Dominant & 0.4427 & $1.69(0.49-5.89)$ \\
\hline & Allelic & 0.0258 & $2.04(1.08-3.86)$ \\
\hline \multirow{4}{*}{ FIS } & Codominant & 0.0122 & $8.98(1.15-69.9)$ \\
\hline & Recessive & 0.1218 & $1.86(0.90-3.84)$ \\
\hline & Dominant & 0.0241 & $7.3(0.97-54.74)$ \\
\hline & Allelic & 0.0251 & $1.94(1.11-3.39)$ \\
\hline \multirow{4}{*}{ NFIS } & Codominant & 0.0170 & $2.45(1.16-5.17)$ \\
\hline & Recessive & 0.0010 & $2.24(1.38-3.63)$ \\
\hline & Dominant & 0.1615 & $1.65(0.81-3.34)$ \\
\hline & Allelic & 0.0022 & $1.75(1.22-2.50)$ \\
\hline \multirow{4}{*}{ Males } & Codominant & 0.4508 & $2.6(0.48-14.23)$ \\
\hline & Recessive & 0.4596 & $1.63(0.62-4.27)$ \\
\hline & Dominant & 0.4804 & $2.19(0.43-11.2)$ \\
\hline & Allelic & 0.2760 & $1.58(0.75-3.29)$ \\
\hline \multirow{4}{*}{ Females } & Codominant & 0.0072 & $2.80(1.30-6.01)$ \\
\hline & Recessive & 0.0011 & $2.24(1.37-3.65)$ \\
\hline & Dominant & 0.0778 & $1.89(0.92-3.88)$ \\
\hline & Allelic & 0.0013 & $1.79(1.25-2.56)$ \\
\hline
\end{tabular}

AIS-adolescent idiopathic scoliosis; JIS-juvenile idiopathic scoliosis; FIS-familial idiopathic scoliosis; NFIS-nonfamilial idiopathic scoliosis; $p$-probability value; $\mathrm{OR}$-odds ratio; $\mathrm{CI}-$ confidence interval.

No family history data from previous studies were available. The separation of cases according to this type of data was necessary because of the possible differences in genetic predisposition to familial and nonfamilial forms of a specific complex disease [21]. Our results suggested that there is genetic predisposition in familial as well as nonfamilial scoliosis, but the smaller sample of familial cases should be further expanded in order to support the conclusion of the current study.

Idiopathic scoliosis occurs more frequently in female than in male subjects [22-25]. Due to this reason, the casecontrol study on the association between TGFB1 and AIS in the Chinese population included only female subjects [12]. In the current subgroup analysis stratified by gender, significant increasing susceptibility to deformity was detected in the general female group as well as in the female subgroups with JIS, AIS, and familial and sporadic forms of scoliosis $(p<0.05)$, but no significant association between TGFB1 $(-509 \mathrm{C} / \mathrm{T})$ and risk of deformity was found in males (see Table 2
TABLE 3: Inheritance models in different female subgroups.

\begin{tabular}{lccc}
\hline Females & Genetic model & $P$ value & OR (95\% CI) \\
\hline \multirow{4}{*}{ General } & Codominant & $\mathbf{0 . 0 0 7 2}$ & $2.80(1.30-6.01)$ \\
& Recessive & $\mathbf{0 . 0 0 1 1}$ & $2.24(1.37-3.65)$ \\
& Dominant & 0.0778 & $1.89(0.92-3.88)$ \\
& Allelic & $\mathbf{0 . 0 0 1 3}$ & $1.79(1.25-2.56)$ \\
AIS & Codominant & $\mathbf{0 . 0 0 9 4}$ & $3.19(1.29-7.86)$ \\
& Recessive & $\mathbf{0 . 0 0 9 3}$ & $2.02(1.18-3.45)$ \\
& Dominant & 0.0477 & $2.32(0.99-5.45)$ \\
JIS & Allelic & $\mathbf{0 . 0 0 4 5}$ & $1.76(1.19-2.60)$ \\
& Codominant & 0.1332 & $3.62(0.77-17.0)$ \\
& Recessive & $\mathbf{0 . 0 0 8 5}$ & $3.36(1.31-8.62)$ \\
& Dominant & 0.3892 & $2.06(0.46-9.26)$ \\
\multirow{3}{*}{ FIS } & Allelic & $\mathbf{0 . 0 2 1 1}$ & $2.35(1.12-4.92)$ \\
& Codominant & $\mathbf{0 . 0 1 7 9}$ & $8.44(1.07-66.8)$ \\
& Recessive & 0.0859 & $1.96(0.90-4.26)$ \\
& Dominant & 0.0359 & $6.64(0.88-50.3)$ \\
& Allelic & $\mathbf{0 . 0 2 2 7}$ & $1.98(1.09-3.58)$ \\
\hline \multirow{4}{*}{ NFIS } & Codominant & 0.0480 & $2.23(1.00-5.00)$ \\
& Recessive & $\mathbf{0 . 0 0 1 8}$ & $2.37(1.37-4.10)$ \\
& Dominant & 0.3623 & $1.42(0.67-3.02)$ \\
& Allelic & $\mathbf{0 . 0 0 8 0}$ & $1.72(1.15-2.57)$ \\
\hline
\end{tabular}

AIS-adolescent idiopathic scoliosis; JIS-juvenile idiopathic scoliosis; FIS-familial idiopathic scoliosis; NFIS-nonfamilial idiopathic scoliosis; $p$-probability value; $\mathrm{OR}$-odds ratio; $\mathrm{CI}-$ confidence interval.

and Table 3). Thus, the previously reported genetic association between TGFB1 $(-509 \mathrm{C} / \mathrm{T})$ and AIS predisposition in female cases from a population sample of European descent [11] was observed in Bulgarian patients.

Additional larger replication studies are necessary to confirm the relationship between the TGFB1 locus and certain subtypes of IS in specific population groups and to detect a potential association between the TGFB1 gene and idiopathic scoliosis in male patients. On the basis of the studies so far, genes encoding TGFB genes and their receptors (TGFBRs) may be included in the candidate-gene group involved in the etiology and pathogenesis of idiopathic scoliosis. Changes in the transcriptional profile of TGFBs and TGFBRs could influence the regulation of many signaling pathways potentially involved in the development and further progression of the deformity [26].

The potential clinical application of the findings for personalized treatment algorithms and improvement of the quality of care by allowing evidence-based management decisions motivated the development of genetic tests such as the ScoliScore AIS Prognostic Test in 2009. It was used to analyze the genotypes of 53 polymorphic markers associated with curve progression in Caucasian male and female patients with mild AIS (10-25 Cobb angle, 9 to 13 years of age) [27]. The test is no longer available after ScoliScore failed in 2 independent analyses conducted in Caucasian and Asian populations [28, 29]. In 2016, Bohl et al. demonstrated that the ScoliScore genetic test correlates with bracing outcome and may be appropriate for future bracing studies [30]. 


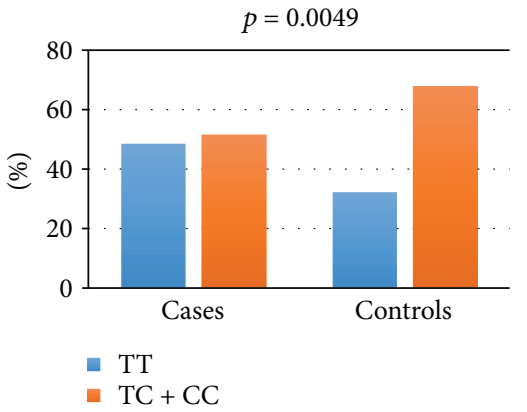

(a)

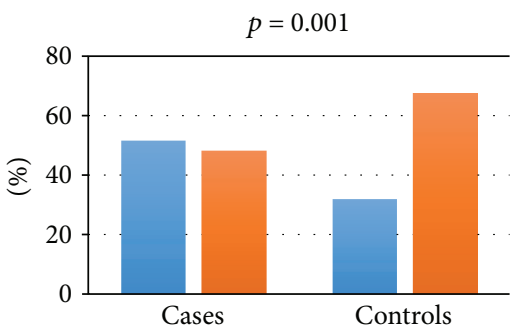

TT

- $\mathrm{TC}+\mathrm{CC}$

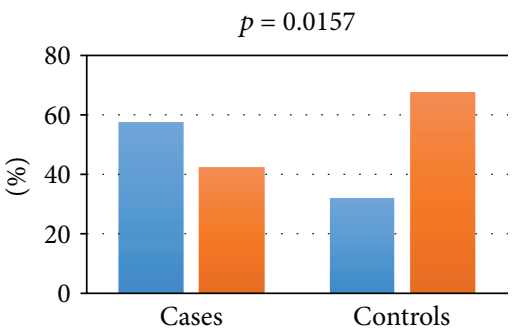

- $\mathrm{TT}$

- $\mathrm{TC}+\mathrm{CC}$

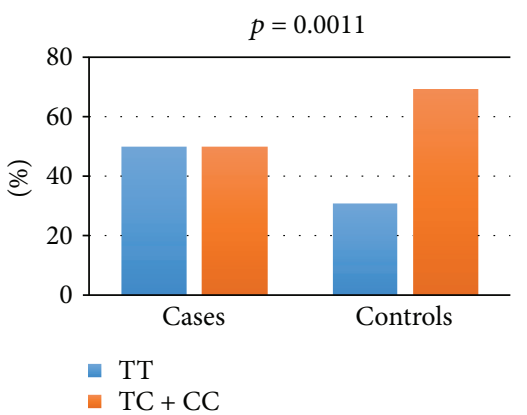

(d)

FIgure 1: Recessive genetic model TT/(TC+CC) in (a) adolescent idiopathic scoliosis (AIS), (b) juvenile idiopathic scoliosis (JIS), (c) nonfamilial idiopathic scoliosis (NFIS), and (d) females.

Additional genetic research could identify predisposing and modifying genetic factors of scoliosis and improve scoliosis prevention and treatment with early less invasive procedures. Providing new information could lead to more effective care with lower cost and fewer unnecessary radiographs and brace applications in the affected individuals [27].

\section{Conclusions}

On the basis of the present results, TGFB1 $(-509 \mathrm{C} / \mathrm{T})$ can be considered as a predisposing factor of idiopathic scoliosis with a moderate individual effect on deformity development in Bulgarian patients.

The current results may suggest that there is an association of the TGFB1 $(-509 \mathrm{C} / \mathrm{T})$ polymorphism with the susceptibility to IS in the female population with sporadic or familial IS and early or late onset IS.

Future extended association studies in different populations are necessary to confirm these findings and to examine the genetic correlates with the disease etiology in males.

The identification of prognostic molecular genetic markers is a contemporary approach that would permit an early treatment, including less invasive surgical or nonsurgical procedures.

\section{Data Availability}

The data used to support the findings of this study are included within the article.

\section{Conflicts of Interest}

The authors declare that there is no conflict of interest regarding the publication of this article.

\section{Acknowledgments}

The authors would like to thank all the participants in the study. This work was supported by the Medical UniversitySofia (Grant no. 5D-2014, Contract no. 2D-2014).

\section{References}

[1] C. L. Raggio, P. F. Giampietro, S. Dobrin et al., "A novel locus for adolescent idiopathic scoliosis on chromosome 12p," Journal of Orthopaedic Research, vol. 27, no. 10, pp. 1366-1372, 2009.

[2] F. Balagué and F. Pellisé, "Adolescent idiopathic scoliosis and back pain," Scoliosis and Spinal Disorders, vol. 11, no. 1, p. 27, 2016.

[3] T. N. Burks and R. D. Cohn, "Role of TGF- $\beta$ signaling in inherited and acquired myopathies," Skeletal Muscle, vol. 1, no. 1, p. 19, 2011.

[4] J. F. Santibañez, M. Quintanilla, and C. Bernabeu, “TGF- $\beta$ / TGF- $\beta$ receptor system and its role in physiological and pathological conditions," Clinical Science, vol. 121, no. 6, pp. 233-251, 2011.

[5] C. G. Zhao, X.-J. He, B. Lu, H.-P. Li, and A.-J. Kang, "Increased expression of collagens, transforming growth factor- $\beta 1$, and - $\beta 3$ in gluteal muscle contracture," BMC Musculoskeletal Disorders, vol. 11, no. 1, p. 15, 2010. 
[6] M. E. Dickinson, M. S. Kobrin, C. M. Silan et al., "Chromosomal localization of seven members of the murine TGF- $\beta$ superfamily suggests close linkage to several morphogenetic mutant loci," Genomics, vol. 6, no. 3, pp. 505-520, 1990.

[7] G. Qiu, Q. Li, Y. Liu et al., "Expression of transforming growth factor- $\beta 1$ and basic fibroblast growth factor in articular process cartilages of adolescent idiopathic scoliosis," Zhonghua Yi Xe Za Zhi, vol. 86, no. 21, pp. 1478-1483, 2006.

[8] H. Xu, G. Qiu, Z. Wu et al., "Expression of transforming growth factor and basic fibroblast growth factor and core protein of proteoglycan in human vertebral cartilaginous endplate of adolescent idiopathic scoliosis," Spine, vol. 30, no. 17, pp. 1973-1978, 2005.

[9] R. Nowak, M. Kwiecien, M. Tkacz, and U. Mazurek, “Transforming growth factor-beta (TGF- $\beta$ ) signaling in paravertebral muscles in juvenile and adolescent idiopathic scoliosis," BioMed Research International, vol. 2014, Article ID 594287, 14 pages, 2014.

[10] R. Shah, C. K. Hurley, and P. E. Posch, "A molecular mechanism for the differential regulation of TGF- $\beta 1$ expression due to the common SNP -509C-T (c. -1347C>T)," Human Genetics, vol. 120, no. 4, pp. 461-469, 2006.

[11] I. I. Ryzhkov, E. E. Borzilov, M. I. Churnosov, A. V. Ataman, A. A. Dedkov, and A. V. Polonikov, "Transforming growth factor Beta 1 is a novel susceptibility gene for adolescent idiopathic scoliosis," Spine, vol. 38, no. 12, pp. E699-E704, 2013.

[12] L. Xu, W. Sun, X. Qin, Y. Qiu, and Z. Zhu, "The TGFB1 gene is associated with curve severity but not with the development of adolescent idiopathic scoliosis: a replication study in the Chinese population," BMC Musculoskeletal Disorders, vol. 17, no. 1, article 15, 2016.

[13] Z. Chen, N. L. S. Tang, X. Cao et al., "Promoter polymorphism of matrilin-1 gene predisposes to adolescent idiopathic scoliosis in a Chinese population," European Journal of Human Genetics, vol. 17, no. 4, pp. 525-532, 2009.

[14] J. Jiang, B. Qian, S. Mao et al., "A promoter polymorphism of tissue inhibitor of metalloproteinase-2 gene is associated with severity of thoracic adolescent idiopathic scoliosis," European Spine Journal, vol. 37, no. 1, pp. 41-47, 2012.

[15] D. Zhao, G. X. Qiu, Y. P. Wang, J. G. Zhang, J. X. Shen, and Z. H. Wu, "Association between adolescent idiopathic scoliosis with double curve and polymorphisms of calmodulin1 gene/ estrogen receptor-a gene," Orthopaedic Surgery, vol. 1, no. 3, pp. 222-230, 2009.

[16] H. Q. Zhang, S. J. Lu, M. X. Tang et al., “Association of estrogen receptor beta gene polymorphisms with susceptibility to adolescent idiopathic scoliosis," European Spine Journal, vol. 34, no. 8, pp. 760-764, 2009.

[17] Y. Peng, G. Liang, Y. Pei, W. Ye, A. Liang, and P. Su, "Genomic polymorphisms of G-protein estrogen receptor 1 are associated with severity of adolescent idiopathic scoliosis," International Orthopaedics, vol. 36, no. 3, pp. 671-677, 2012.

[18] H. Y. Yeung, N. L. Tang, K. M. Lee et al., "Genetic association study of insulin-like growth factor-I (IGF-I) gene with curve severity and osteopenia in adolescent idiopathic scoliosis," Studies in Health Technology and Informatics, vol. 123, pp. 18-24, 2006.

[19] E. S. Moon, H. S. Kim, V. Sharma et al., "Analysis of single nucleotide polymorphism in adolescent idiopathic scoliosis in Korea: for personalized treatment," Yonsei Medical Journal, vol. 54, no. 2, pp. 500-509, 2013.
[20] Y. Takahashi, I. Kou, A. Takahashi et al., "A genome-wide association study identifies common variants near LBX1 associated with adolescent idiopathic scoliosis," Nature Genetics, vol. 43, no. 12, pp. 1237-1240, 2011.

[21] P. Donaldson, A. Daly, L. Ermini, and D. Bevitt, Genetics of Complex Disease. Garland Science, Taylor and Francis Group, LLC, New York, NY, USA, 2016.

[22] P. Kamtsiuris, K. Atzpodien, U. Ellert, R. Schlack, and M. Schlaud, "Prevalence of somatic diseases in German children and adolescents. Results of the German Health Interview and Examination Survey for Children and Adolescents (KiGGS)," Bundesgesundheitsblatt, Gesundheitsforschung, Gesundheitsschutz, vol. 50, no. 5-6, pp. 686-700, 2007.

[23] J. S. Daruwalla, P. Balasubramaniam, S. O. Chay, U. Rajan, and H. P. Lee, "Idiopathic scoliosis. Prevalence and ethnic distribution in Singapore schoolchildren," Journal of Bone and Joint Surgery. British Volume, vol. 67-B, no. 2, pp. 182-184, 1985.

[24] K. Cilli, G. Tezeren, T. Taş et al., "School screening for scoliosis in Sivas, Turkey," Acta Orthopaedica et Traumatologica Turcica, vol. 43, no. 5, pp. 426-430, 2009.

[25] L. S. Nery, R. Halpern, P. C. Nery, K. P. Nehme, and A. Tetelbom Stein, "Prevalence of scoliosis among school students in a town in southern Brazil," São Paulo Medical Journal, vol. 128, no. 2, pp. 69-73, 2010.

[26] J. Massagué, "How cells read TGF- $\beta$ signals," Nature Reviews Molecular Cell Biology, vol. 1, no. 3, pp. 169-178, 2000.

[27] J. Ogilvie, "Adolescent idiopathic scoliosis and genetic testing," Current Opinion in Pediatrics, vol. 22, no. 1, pp. 67-70, 2010.

[28] Q. L. Tang, C. Julien, R. Eveleigh et al., "A replication study for association of 53 single nucleotide polymorphisms in ScoliScore test with adolescent idiopathic scoliosis in FrenchCanadian population," Spine, vol. 40, no. 8, pp. 537-543, 2015.

[29] Y. Ogura, Y. Takahashi, I. Kou et al., "A replication study for association of 53 single nucleotide polymorphisms in a scoliosis prognostic test with progression of adolescent idiopathic scoliosis in Japanese," Spine, vol. 38, no. 16, pp. 1375-1379, 2013.

[30] D. D. Bohl, C. J. Telles, F. K. Ruiz, R. Badrinath, P. A. DeLuca, and J. N. Grauer, "A genetic test predicts providence brace success for adolescent idiopathic scoliosis when failure is defined as progression to $>45$ degrees," Clinical Spine Surgery, vol. 29, no. 3, pp. E146-E150, 2016. 


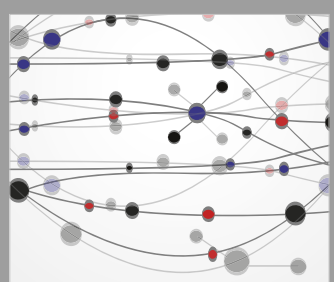

The Scientific World Journal
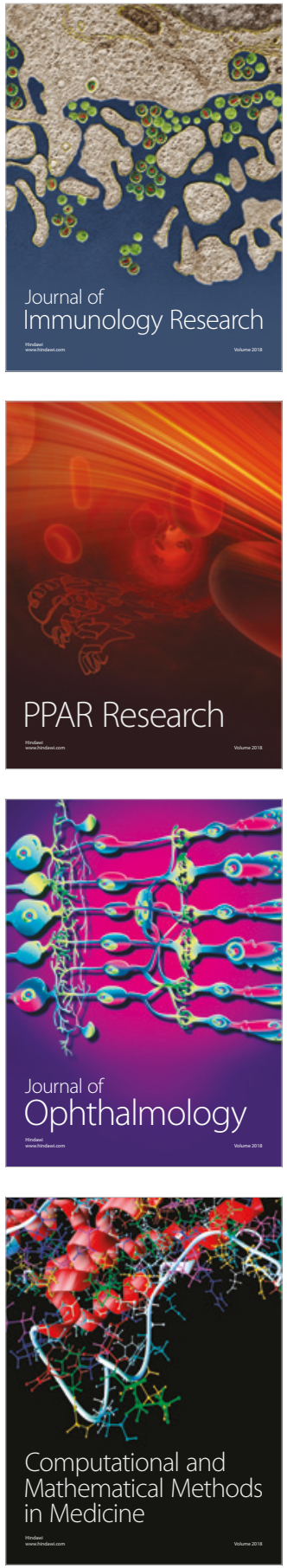

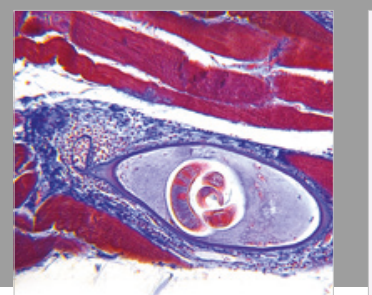

Gastroenterology Research and Practice

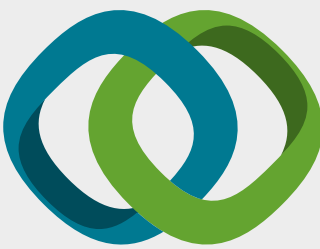

\section{Hindawi}

Submit your manuscripts at

www.hindawi.com
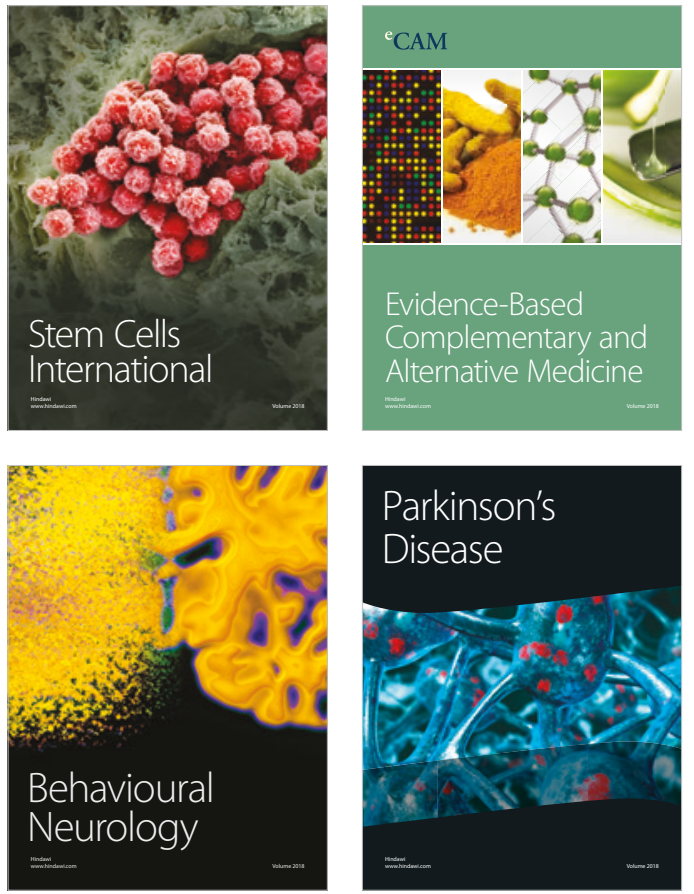

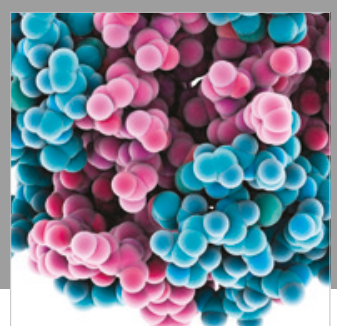

ournal of

Diabetes Research

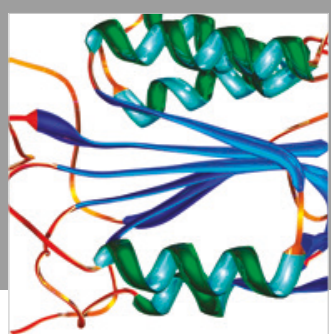

Disease Markers
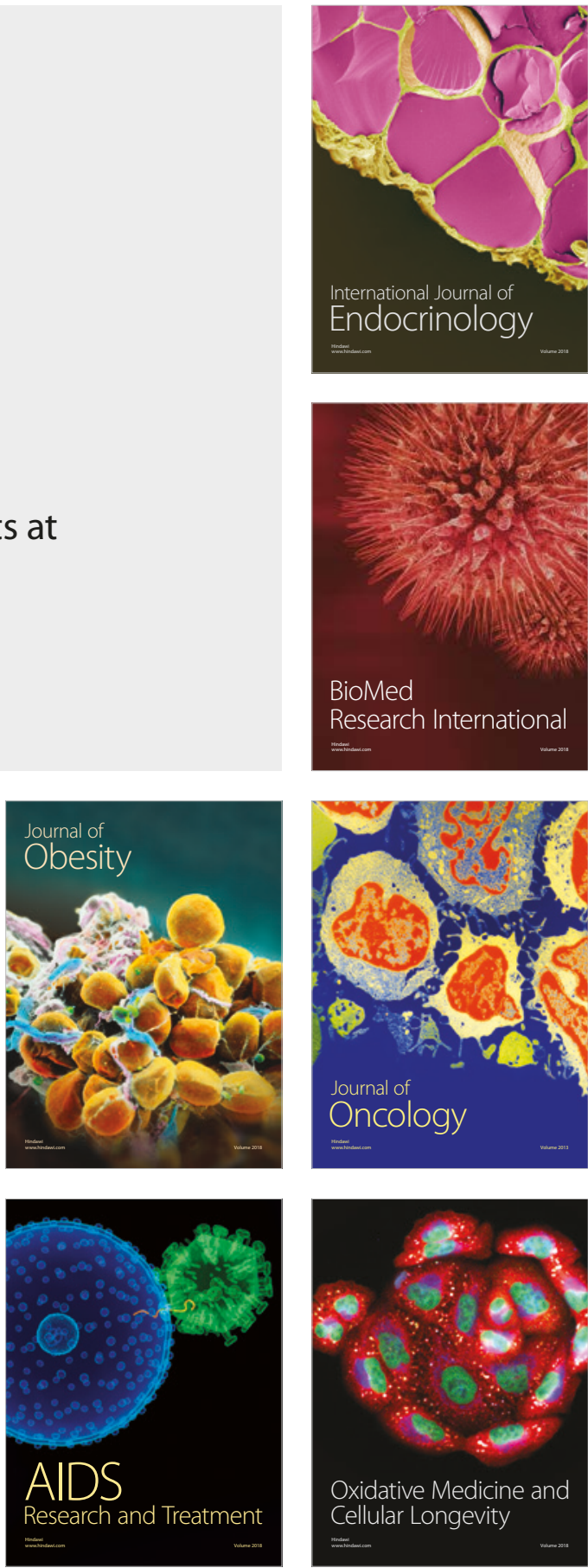